emphasise another potential danger of additives in parenteral solutions and to underline the desirability of using prepared solutions of known concentration. ${ }^{1}$

Full details of this patient's condition may be obtained from GG.

Ellis, B W, et al, British Medical fournal, 1976, 1, 1388.

2 Kay, R G, et al, Annals of Surgery, 1976, 183, 331.

${ }^{3}$ Polson, C J, and Tattersall, R N, Clinical Toxicology. London, Pitman, 1969.

4 Gallery, E M, Blomfield, J, and Dixon, S R, British Medical fournal, 1972, 4, 331.

5 Spencer, $\mathrm{H}$, et al, in Zinc Metabolism, ed A S Prasad. Springfield, Thomas, 1966.

(Accepted 7 February 1977)

St Mary's Hospital, London W2

ASHLEY BROCKS, DCH, FRCS, registrar in surgery

H REID, MB, MRCPATH, senior registrar in histopathology

G GLAZER, MB, FRCs, consultant surgeon

\title{
Reiter's disease after Salmonella typhimurium enteritis
}

I report possibly the first case of Reiter's disease after Salmonella typhimurium enteritis.

\section{Case report}

A 12-year-old girl was admittted to hospital in February 1976 with an acute polyarthritis. Two weeks previously she had developed frequent loose bloody stools, for which she had been given a kaolin and neomycin mixture, the diarrhoea settling after one week. She then remained well until three days before admission, when her mother noticed that her right eye looked inflamed. She also had terminal burning on micturition but no frequency. Two days before admission she developed painful swelling of the left knee, right elbow, and right wrist.

She did not look ill but her temperature was $38 \cdot 8^{\circ} \mathrm{C}$. She had bilateral conjunctivitis and mild pharyngitis. The left knee was hot, red, and swollen with an obvious effusion, and pain limited flexion to $40^{\circ}$. The right wrist and elbow were also hot and swollen with limited movement. There was no rash or lymphadenopathy, and the urethral orifice did not look inflamed. She had a tachycardia of $130 / \mathrm{min}$ and a moderate midsystolic ejection murmur. Haemoglobin was $14.0 \mathrm{~g} / \mathrm{dl}$; white cell count $10.9 \times 10^{9} / 1(10900 /$ $\mathrm{mm}^{3}, 82 \%$ neutrophils; and erythrocyte sedimentation rate $50 \mathrm{~mm}$ in the first hour. Stool culture grew $S$ typhimurium, phage type U129-014. Aspirate from the left knee joint was cloudy, contained polymorphs but no organisms, was sterile on culture, and had a protein content of $51 \mathrm{~g} / 1$. Radiographs of affected joints, feet, and sacroiliac joints were normal. Antistreptolysin titre, tests for rheumatoid and antinuclear factors, gonococcal complement fixation test, Wassermann reaction, and tine test were negative. Throat swab and urine and blood cultures were sterile. Chest $x$-ray appearances and electrocardiogram were normal. HLA typing yielded A2, AW19, B7, and $\mathrm{B} 27$.

She was treated with bed rest and small doses of aspirin, and when the stool culture report was obtained ampicillin was started. The conjunctivitis and dysuria cleared rapidly but she developed tenderness of the left heel and inflammation of the left ankle and right knee joints. During the nex 10 days her joint symptoms fluctuated and over the next month gradually settled. One month after admission fever, abdominal pain, and diarrhoea developed and $S$ typhimurium was again isolated from her stools, but her joint symptoms did not relapse.

One year after the initial illness she was well and fully mobile and her stools were free of salmonellae. She had some residual synovial thickening in the right knee joint.

\section{Comments}

In 1916 Hans Reiter described a soldier who developed the triad of conjunctivitis, urethritis, and polyarthritis after an attack of bloody diarrhoea. Since then the disease has been described in many adults after shigella dysentery and also after non-gonococcal urethritis. A few cases have occurred in children, mostly after diarrhoeal illnesses. In salmonellosis a bacterial arthritis may occur, the organism usually

being cultured from the joint fluid. ${ }^{2}$ In addition a non-bacterial reactive arthritis has been described ${ }^{3}$ and shown to be associated witn HLA-B27, which is commonly found in Reiter's disease. Vartiainen and $\mathrm{Hurri}^{3}$ described 12 patients in whom polyarthritis followed infection with $S$ typhimurium, one of them also having conjunctivitis and iritis. Berglöf ${ }^{4}$ described a man with $S$ typhimurium infection who developed polyarthritis, conjunctivitis, urethritis, and prostatitis and had $x$-ray changes in the sacroiliac joints. Neither paper mentioned Reiter's disease. So far as I know there have been no published case reports of Reiter's disease with salmonella infections, but in both my case and Berglöf's the association of diarrhoea with polyarthritis, conjunctivitis, and urethritis must warrant this title.

I thank Dr H V L Finlay for permission to report this case and for advice and encouragement.

1 Moss, I S, British Fournal of Venereal Diseases, 1964, 40, 166

2 David, J R, and Black, R L, Medicine, 1960, 39, 385.

${ }^{3}$ Vartiainen, J, and Hurri, L, Acta Medica Scandinavica, 1964, 175, 771

4 Berglöf, F-E, Acta Rheumatologica Scandinavica, 1963, 3, 141.

5 Aho, K, et al, Annals of the Rheumatic Diseases, 1975, 34, suppl No 1, p 29.

(Accepted 9 February 1977)

Department of Paediatrics, Hillingdon Hospital, Middlesex

ROSAMOND A K JONES, MRCP, registrar (present address: Hammersmith Hospital, London W12 OHS

\section{Tetrabenazine in Sydenham's chorea}

Tetrabenazine is a reserpine-like compound which has an established place in the treatment of Huntington's chorea. ${ }^{12}$ We report two cases of rheumatic chorea in which involuntary movements were dramatically improved by this drug.

\section{Case reports}

Case 1-A 10-year-old girl was admitted to hospital with a five-month history of difficulty in walking, slurred speech, and inability to dress herself. Her speech was severely dysarthric, and there were widespread coarse choreic movements of all limbs, which made it impossible for her to stand or to use her arms for any purposive movement. She was tearful but there were no signs of intellectual impairment. The cardiovascular system was normal and full blood count, erythrocyte sedimentation rate, measurement of electrolyte concentrations, liver function tests, antistreptolysin $O$ titre, and chest radiography showed nothing abnormal. Treatment was begun with tetrabenazine $25 \mathrm{mg}$ three times daily. Within 24 hours there was a dramatic improvement in speech and involuntary movements and after a few days she could walk and dress herself. Depression or other unwanted effects were not observed. The movements almost completely resolved after about two weeks and the medication was discontinued one month later. When last seen three years after her illness she was maintaining good health but small choreic movements were still evident.

Case 2-A 12-year-old boy was admitted to hospital with a three-week history of stiff and painful joints in the arms and legs. This resolved in two and a half weeks, but was replaced by severe, widespread, coarse choreic movements in all limbs. Feeding was impossible and he could barely walk with the aid of one person. A faint cardiac systolic murmur was detected at the apex. The anti-streptolysin $O$ titre was raised at $600 \mathrm{IU} / \mathrm{ml}$. Ful blood count was normal and erythrocyte sedimentation rate was $44 \mathrm{~mm}$ in the first hour. Chest radiography and electrocardiogram were both normal Initial treatment consisted of penicillin and diazepam which had little effect on the chorea. After one week diazepam was stopped and tetrabenazine $25 \mathrm{mg}$ twice daily was given. This resulted in a dramatic lessening of involuntary movements within 24 hours, and after one week's treatment they were minimal and he could walk and feed himself unaided. Tetrabenazine was discontinued after three months. Depression was not observed and he was free from chorea until four months after discharge when he had a further episode of joint pain and chorea which again responded to tetrabenazine.

\section{Comment}

The important features shown in these two cases were the rapidity and specificity of the action of tetrabenazine. The movements were 